ORIGINAL ARTICLE

AFRICAN JOURNAL OF CLINICAL AND EXPERIMENTAL MICROBIOLOGY AJCEM/21303

COPYRIGHT 2013 http://dx.doi.org/10.4314/ajcem.v14i1.4

JANUARY2013 ISBN 1595-689X VOL 14(1) 2013

AFR. J. CLN. EXPER. MICROBIOL 14(1): 14-18 -http://www.ajol.info/journals/ajcem

\title{
ANTIBACTERIAL ACTIVITIES OF DIFFERENT BRANDS OF DEODORANTS MARKETED IN OWERRRI, IMO STATE, NIGERIA
}

EGBUOBI ${ }^{1}$, R. C., OJIEGBE ${ }^{1}$, G. C., DIKE-NDUDIM ${ }^{1}$, J.N. \& ENWURU² P. C.

1, DEPARTMENT OF MEDICAL LABORATORY SCIENCE, IMO STATE UNIVERSITY, OWERRI. 2, ST JOHNS MEDICAL LABORATORY, OWERRI.

CORRESPONDENCE: EGBUOBI R. C. P. O. BOX 3739, OWERRI E- mail address: neekyrichy@yahoo.com.

\section{ABSTRACT}

Body odour caused by bacterial growth is of great concern to those affected. To ameliorate this, deodorants, which are substances applied to avert body odour, are designed and used. These deodorants are claimed to have antibacterial activities. This work was therefore, carried out to determine the antibacterial activities of the deodorants marketed in Owerri municipality. Owerri is the capital of Imo State of Nigeria. To determine this, twenty (20) deodorants from ten (10) different manufacturers made up of fourteen (14) roll-on and six (6) sprays were assessed using punch -hole plate diffusion technique on nutrient agar plates. The deodorants were purchased from Ekeonunwa market, New market, Relief market, and some supper markets, all in Owerri Municipality. These deodorants were tested against Laboratory isolates of Staphylococcus epidermidis, Pseudomonas aeruginosa, Escherichia coli and Proteus mirabilis obtained from Federal Medical Centre (FMC) and Modesty Medical Laboratory Owerri and reconfirmed using morphological and biochemical tests. Out of the twenty (20) deodorants tested, 18 $(90 \%)$ were active against the organisms, $17(85 \%)$ were active against Staphylococcus epidermidis, 15 (75\%) against $P$. mirabilis, 11 (55\%) against $E$. coli and $10(50 \%)$ against $P$. aeruginosa. It was also observed that deodorants "roll - on" were more active $14(100 \%)$ than the deodorants "sprays" 4 (66.6\%). From this study, it was observed that the deodorants tested had antibacterial activities.

Key words: Deodorants, Antibacterial, body, odor 


\section{INTRODUCTION}

Deodorants are substances applied to the body to affect body odour caused by bacteria growth and the smell associated with bacterial breakdown of perspiration in armpits, feet and other body areas ${ }^{1}$. A sub group of deodorants, 'antiperspirants', affect odour as well as prevent sweating by affecting sweat glands. Antiperspirants are typically applied to the underarms, while deodorants may also be applied on the feet and other areas in the form of body sprays ${ }^{2}$.

Human perspiration is largely odourless until it is fermented by bacteria that thrives in hot, humid environments 3 . The human underarm is among the most consistently warm areas on the surface of the human body, and sweat glands provide moisture, which when excreted, has a vital cooling effect. When adult armpits are washed with alkaline $\mathrm{PH}^{\mathrm{H}}$ soap, the skin loses its acid mantle $(\mathrm{PH} 4.5$ - 6), raising the skin $\mathrm{PH}$ and disrupting the skin barrier ${ }^{4}$. Many bacteria thrive in this elevated $\mathrm{PH}^{\mathrm{H}}$ environment ${ }^{5}$. These bacteria feed on the sweat from the apocrine glands and on dead skin and hair cells, releasing trams -3-methyl-2- hexenoic acid in their waste which is the primary cause of body odour ${ }^{6}$. Underarm hair wicks the moisture away from the skin and aids in keeping the skin dry enough to prevent or diminish bacterial colonization. The hair is less susceptible to bacterial

growth and therefore is ideal for preventing the bacterial odour ${ }^{7}$. While deodorants, reduce body odour by killing the odour causing bacteria, they do not affect the amount of perspiration the body produces. Antiperspirants, on the other hand inhibit the activity of sweat glands, so less moisture is produced in addition to avoiding unpleasant wetness. These products also decrease odour because there are less sweat for the bacteria to act upon ${ }^{8}$.

The terms 'deodorants' and "antiperspirants" are often used interchangeably, although they describe two different products. While the most frequent active ingredient in commercial antiperspirants are Aluminium chlorohydrate and Aluminium zirconium tetrachorohydrate gly, deodorants are usually alcohol-based, containing some antimicrobial agents such as Fernesole, triclosan, Paraben, Zinc riconoleate, trieltyl citrate, chlorophyllin copper complex and other metal, chalent compounds that slow bacterial growth $9,10,11$.

Deodorants exhibit their antimicrobial activities, by reducing the body $\mathrm{PH}$ which in turn inhibits the growth of microorganisms that produce malodour ${ }^{12}$. Another difference between deodorants and antiperspirants is that, while deodorants are considered to be cosmetics products because they only control odour, antiperspirants are actually drugs because they affect the physiology of the body ${ }^{13}$. The first ever deodorant was produced by zingal in the $9^{\text {th }}$ Century in Al-Andalus ${ }^{14}$. Ever since then modernizations have been going on, with some criticisms from the US food and Drug Administration (FDA) and Environmental protections Agency (EPA) which brought about what we now have in the market as present day deodorants.

Deodorants and antiperspirants come in many forms. What is commonly used, varies from country to country. In Europe, aerosol sprays are popular, as are cream and roll-on forms. In the United State, solid or gel forms are dominant. And in Nigeria (especially Owerri), both the sprays and the roll-on brands are common. Many people use and believe in the antibacterial effectiveness of these deodorants, which they hope will prevent or reduce the body odour.

This work therefore, was carried out to determine the antibacterial effect of these deodorants marketed in Owerri, the capital of Imo State of Nigeria.

It is also aimed at comparing the level/degree of efficacy between the two brands marketed in Owerri.

\section{MATERIALS AND METHODS ORGANISM}

The organisms used were laboratory isolates such as Staphylococcus epidermidis, (skin normal flora) Preteus mirabilis, Pseudomonas aeruginosa and Escherichia coli which were obtained from Federal Medical Center Owerri (FMC) and Modesty Medical Laboratory Owerri in Imo State of Nigeria from June - November 2011. The organisms were tested, using standard discs and were found to have zones of inhibition of more than $15 \mathrm{~mm}$ diameter against pencillin, ampicillin, gentamycin and ampicillin respectively.

These isolates were reconfirmed before being used in this research work. The reconfirmation was done in Modesty Medical Laboratory following the conventional method of identification such as Morphological, Grams staining reaction technique, Motility and Biochemical methods.

\section{PREPARATION OF DEODORANT}

A total of twenty (20) deodorants from ten (10) different manufacturers were tested. They were made up of fourteen roll-ons $\left(R_{1}-R_{14}\right)$ and six sprays $\left(S_{1}-S_{6}\right)$.The deodorants were selected randomly. The fluid of each deodorant roll-on, was aspirated aseptically into sterile tubes.

While that of the spray was sprayed into a sterile container before been used for this work.

\section{SUSCEPTIBILITY TESTING}

Plate diffusion technique using the punch-hole method was adopted, oxoid nutrient agar medium which was used was prepared and sterilized according to the manufacturer's instruction. The nutrient agar plates were inoculated with the bacteria, each plate for each bacterium but was done in duplicate.

The plates were inoculated with the organism after dilution to give about $10^{6}$ cells $/ \mathrm{ml}$. Punch holes were made using sterile cock borer of $10 \mathrm{~mm}$ diameter. Each hole was labelled against the deodorant and filled, allowed to stay for about 30 minutes before incubation at $37^{\circ} \mathrm{C}$ for 18 hours. Zones of inhibition were measured using mm ruler. Any deodorant giving an inhibition zone of more than $2 \mathrm{~mm}$ on either side of the hole was regarded as having antibacterial activity.

\section{RESULTS}

The antibacterial activities of twenty (20) deodorants from ten (10) different manufacturers consisting of fourteen (14) roll-ons and six (6) sprays were assessed using agar diffusion 
punch - hole technique against Staphylococcus epidermidis, (skin normal flora), Proteus mirabilis, Escherichia coli and Pseudomonas.aeruginosa. Diameter of the zones of inhibition was measured. Zones less than $2 \mathrm{~mm}$ on either sides of the hole were considered resistant.

Out of the twenty (20) deodorants that were tested against the organisms, $18(90 \%)$ have zones of inhibition greater than $2 \mathrm{~mm}$ on each side. Seventeen 17 (85\%) showed antibacterial activity against $S$. epidermides, fifteen $15(75 \%)$ inhibited $P$. mirabilis. Eleven 11 (55\%) was active against E. coli and 10 (50\%) inhibited P. aerugenosa.

All the deodorants that were active against $S$. epidermides showed zones of inhibition above $5 \mathrm{~mm}$, except $R_{4}, R_{14}, S_{1}$ and $S_{2}$ that had $2 \mathrm{~mm}$ zones of inhibition each and $R_{11}$ showed the highest zone of inhibition $(15 \mathrm{~mm})$ against $S$. epidermidis.

$P$. aerugenosa was the least sensitive of all the organisms to the deodorants, $10(50 \%)$. Out of the ten deodorants that were active against it, $R_{8}$ and $R_{10}$ showed the highest zone of inhibition $13 \mathrm{~mm}$ each.

Among the fourteen (14) roll-on deodorants assessed, eleven $11(78.6 \%)$ showed zones of inhibition against all the organisms, fourteen $14(100 \%)$ were active against $S$. epidermides, ten $10(71.4 \%)$ against $P$. aerugenosa, Eleven 11 (78.6\%) against E.coli and fourteen $14(100 \%)$ against $P$. mirabilis. Comparing the six (6) spray deodorants assessed, none $(0 \%)$ was active against all the organisms, but $3(50 \%)$ were active against $S$. Epidermides, two $2(33.3 \%)$ against $P$. mirabilis. None $(0 \%)$ was active against $P$. aerugenosa, and E.coli,

\section{DISCUSSION}

This work aimed primarily to determine the antibacterial activities of different brands of deodorants marketed in Owerri metropolis of Imo State, Nigeria, as well as comparing the level/degree of efficacy between the two brands marketed in Owerri

The deodorants roll-on, $R_{11}, R_{8}$, and $R_{10}$ were discovered to have higher level of activity to all the four tested organisms with $\{(15,8,10,15), \quad(14,13,15,14)$, and $(13,13,13,12)\} \mathrm{mm}$ diameter respectively. This peculiar high levels of zones of inhibition reveals the antibacterial efficacies of their various active ingredients (such as triclosan, fanesole, paraben, triethyl citrate and so on). Such level of antimicrobial activity is desirable in the production of deodorants ${ }^{15}$, and possession of acceptable level of antimicrobial activity by super critical Hops extract have been used as natural deodorants ${ }^{16}$.

$R_{4}, R_{13}$, and $R_{14}$ on the other hand showed no zone of inhibition to some of the organisms $\{(2,0,0,4)(9,0,0,6)$ and $(2,0,0,2)\} \mathrm{mm}$ diameter respectively. This could mean that their various active ingredients are contained in low concentrations. This is proven by the statement that some bacterial species can develop low level resistance to triclosan at its low bacteriostatic concentrations due to Fable mutations which results in a decrease to triclosan's effect on ENR-NAD + binding17,18.
Considering sprays, only four sprays $\left(S_{1}, S_{2}, S_{4}, S_{5}\right)$ showed zones of inhibition to some of the organisms and among the four sprays that showed the zones of inhibition, only $S_{5}$ showed appreciable zone of $6 \mathrm{~mm}$ diameter to two of the organisms, others showed zones less than $3 \mathrm{~mm}$ diameter each to one of the organisms only. This may be attributed to the fact that their various active ingredients are contained in very low concentration, regardless of the fact that they were listed on the containers of the sprays in their right proportions. This is in agreement with 19 who stated that 'Another way for these bacteria to gain low-level resistance to triclosan is to over express fable because some bacteria have innate resistance to triclosan at low bacteriostatic level.

Again, the proportion of the ingredients may be in their right order, but, because they are in their gaseous states, they do not have long time of contact with the organisms before they evaporate, thereby bringing the concentration in contact with the organism lower than what it should be. This is also in agreement with ${ }^{19}$.

Then, looking at the susceptibilities of the test organisms used, the high level of susceptibility shown by Staphylococcus epidermidis (85\%) could be related to the fact the organism is a normal flora of the skin which is the primary target of deodorants production. Staphylococcus along side with Corynebacterium and Propionibacterium were listed as the notable bacterial skin normal flora ${ }^{20}$.

Pseudomonas aerugenosa showed the lowest susceptibility $(50 \%)$ to all the deodorants tested. Some of deodorants tested were found to have $(0 \%)$ activeness against it. This could be because $P$. aerugenosa posses multi-drug efflux that pumps triclosan out of the cells 21,22

\section{CONCLUSION AND RECOMMENDATIONS}

In conclusion, we confirm that Deodorants in Owerri market are active against bacterial growths associated with breakdown of perspiration in armpits, feet, and other areas of the body to produce body odour.

We therefore recommend the use of deodorants to control the body odour caused by bacterial breakdown of lipid and protein in sweat, especially during the Adolescent and adult stages of life, when the apocrine gland is developed and produces sweat rich in protein and fatty acid.

We also recommend to the manufacturers, that enough active ingredients be added in the production of different brands of deodorants to enable them achieve their primary aim of production.

Finally we recommend that the National Agency for Food and Drug Administration and Control (NAFDAC) and the Consumers Protection Council (CPC) should rise up to their responsibility of ensuring that the ingredient listed on the containers of these deodorants and their concentrations are actually corresponding to their real contents to avoid deceiving the poor masses. Also further monitoring researches be done on this aspect. 


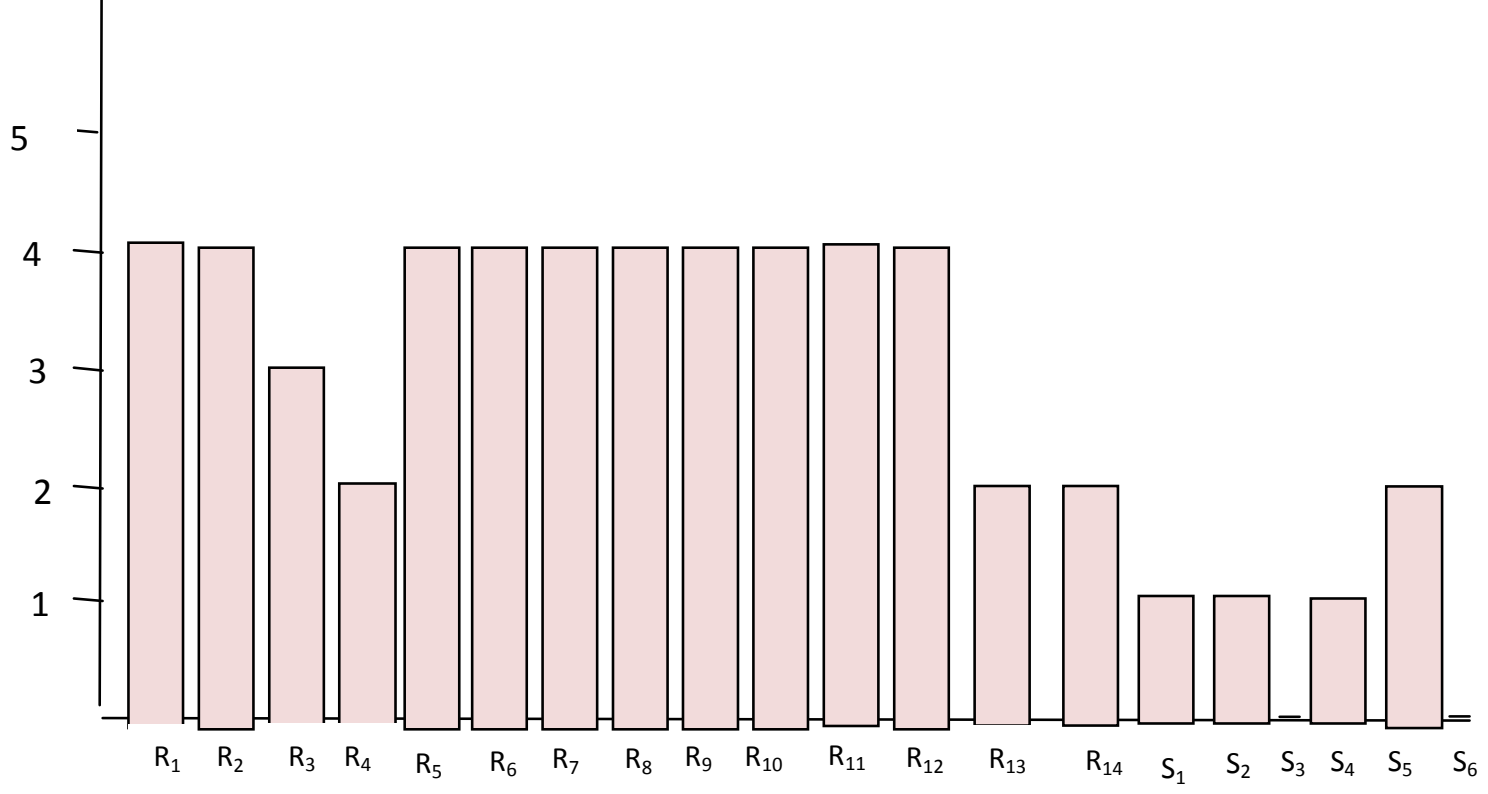

Fig 1: Shows each deodorant and number of organisms affected.

No. of deodorants

$\underline{\text { Key: }} \mathrm{R}_{1 \ldots \ldots . . .} \mathrm{R}_{14}=$ Roll on brands of deodorants (1-14); $\mathrm{S}_{1 \ldots \ldots \ldots . .} \mathrm{S}_{6}=$ spray brand of deodorants (1- 6$)$

\section{REFERENCES}

1. Ashley, R.C. Efficacy of the antimicrobial agent triclosan in tropicdeodorant products: Recent Developements "in viro" (1987). Journal of Soc. Cosmet. Chem. 38: 223- 231.

2. U.S food and Drug Administration Cosmetic $\mathrm{Q}$ and $\mathrm{A}$ : personal care products. (2010).

3. Arak. Hama; M. Akibas. Foot odour due to microbial

metabolism and its control (2006). can. Journal microbial 52 :357- 364.

4. Kuehl, B. L.; Fyte, K. S.; Shear, N. H. Cutanous cleanser. (2003). Skin therapy let 8: 1-4

5. Stenzaly- Achtant, S.; scholoermann, A.; Schreiber, J.; Diec, K. H.;

Ripple, F.; Bielfeldt. Axillary $\mathrm{pH}$ and influence of deodorants. (2000) Skin RE technol 6:87-91.

6. Pierce, J. D. JR.; Aronov, E. V.; Preti, G.; Wysocki, C. J. Cross

adaptation of sweet smelling 3-Methlyl-2hexenoic acid by a structurally similar pleasant smelling deodorant. (1995). Chem. Sences 2094: 401-411.
7. Marc, P.; Howard, I. M.; Andre, O. B. Handbook of cosmetic science and technology3rd Ed. (2009). informs Health Care P. 703. USA.

8. Mirick, D. K.; Davis, S.; Thomas, D. B. Antiperspirants, use and the risk of breast cancer (2002). Journal of Nation al Cancer Inpt 94:1578-1580.

9. Lukacs, V. A.; Korting, H. C. Antiperspirants and deodorant ingredients and evaluation (in German). (1989). Dermatosen in Bemf und Umwelt 37:53-57.

10. Von Woedtke, T.; Schluter, B.; Pflegel, P.; Lindequist, U.; Julich,W. D. Aspect of the antimicrobial Efficacy off grapefruit seed extract and its relation to preservative substances contained. Pharmazie (Graswald Germany): (1999). Institute of pharmacy, Ernst moriz Amdt University 54:452-456.

11. Kromidas, I.; Peiriew, E.; Flanagan, J.; River, O. R.; Bonnet, I. Release of antimicrobial activities from microcapsule by the action of axillary bacteria.(2006). International Journal Cosmeticas Science 28:103-108.

12. Time magazine. Corporations: Scalping the Competition 
1963.http//www.time.com./Time/magazine/article/ 09/71/940327.00html.

13. Drug and cosmetics Industry. Flexibility is the hallmark offluid packaging (1996) p 98.

14. Salma Khada; Jayyusi Manuela Mann. The legacy of muslim (1994). Brill publishers $\mathrm{p}$ 117 Spain.

15. Aviva, G. The ubiquitous Triclosan. (2004). 24: 12-17.

16. Elizabeth, R.D.; Army, E.; Michand, CB.; Jernifer, L.; Sussan, M.; Stetan G. Deodorant effects of a Supercritical hops extract: Antibacterial activity against cornebaterium xerosis and staphylococcus epidermidis and efficacy testing of a hops/zinc ricinoleate stick in humans through the sensory evaluation of auxillary deodorancy. (2009). Journal of Cosmetic Dermatology 8:197-204.

17. Heath, R.J.; Rubin, J.R.; Hollan, D.R.; Zharg, E.; Snou, M.E.; Rock, C.O. Mechanism of Triclosan inhibition of Bacterial fatty acid synthesis. (1999). Journal of Biochemistry 27:1110-1114.
18. Fan, F.; Yan, K.; Wallis, N. G. Defining and combating the

mechanisms of Triclosan Resistance in clinical isolates of Staph. aureaus. (2002). Antimicrobial Agents chemother 46: 3343-3347.

19. Chuanchuen, R.; Karhoft-schweizer, H.P. High-level triclosan resistance in Pseudomonas aeruginosa is solely a result a result of efflux. (2003). American Jour al of Infection Control 31:124-127.

20. Talaro, K,; Talaro, A. Introduction inMicrobiology 2nd Ed. (1996) Mc Graw-Hill publisher P388 New York.

21. Cooper, M.; Tavankar, G.R.; Willians, H.D. Regulation of Expression of the Cyanide insensitive terminal oxidase in pseudomonas aeruginosa microbiology (2003). 149:1275, 1284.

22. 22. Slater-Radostic; Van Aller, G.; Green wood, R.

Biochemical and genetic characterization of the action of triclosan on Staph. aureaus. (2001). Journal of Antimicrobial chemolter 48:16. 